\title{
Masculinity and Femininity in the Attractiveness of Human Face's Preference According to Menstrual Cycle Phase, Contraceptives Intake, and Actual Partnership
}

\author{
Lenka Selecká \\ Psychology department, Faculty of Arts \\ University of Ss. Cyril and Methodius in Trnava, Slovakia
}

\begin{abstract}
Stable personality traits and affections have the potential to be reflected in specific facial traits. Masculine facial characteristics in men are associated with immunological competence and as well with pursuing short-term relationships, therefore a lower possibility to be a good partner. Feminine facial traits in women are connected with health and reproductive ability. Therefore, it could be assumed, dimorphic traits of the evaluated face could be important in attractiveness assessment. The main focus of this research is, how women's menstrual cycle phase, contraceptive intake, and the presence of actual partnership is connected to attractiveness assessment of a face. Research is based on the attractiveness assessment of male and female face composites stressing the features of masculinity and femininity. The research sample consists of 260 women $(M=21.23 y ; S D=6.135)$. The most preferred female face is feminine $(N=200 ; 76.9 \%)$. The preference of male face is not as straightforward; slightly more preferred is a masculine male face $(N=135 ; 52.1 \%)$. Results suggest there is a connection between attractiveness assessment and menstrual cycle, the connection is present for both faces' preferences only in natural menstrual cycle (not using hormonal contraceptives) and simultaneously when the women are not in a partnership. Oral contraception appears to be important in the attractiveness evaluation of a human face, because this condition eliminates the differences present in natural menstrual cycle.
\end{abstract}

Keywords: face attractiveness, masculinity, femininity, female choice, menstrual cycle phase, contraceptives, partnership.

Acknowledgements: This work was supported by the Slovak Research and Development Agency under the contract No. APVV-15-0294.

\section{INTRODUCTION}

Answer to the question what women prefer while making a decision about attractive faces is in the centre of attention in several researches. In general, bilateral symmetry of physical traits is thought to be an important predictor for attractiveness assessment. An interconnection between certain personal characteristics and facial traits can be found, since stable personality traits have the potential to be reflected in specific facial traits. Therefore, faces high in symmetry which are primarily perceived as more attractive, and healthy, are as well perceived as having positive personality attributes. It could be assumed, that women make their choices by estimation of people's personal characteristics, which are unconsciously perceived and evaluated from their face - based on the image of physical beauty.

As is known, watching a beautiful face activates brain reward centers [1] [2], and through mentioned mechanism of reward centers enhancement, attractive faces could motivate sexual behaviour and the establishing of friendships/same-sex alliances [3]. In general, attractive people are seen in a positive light for a wide range of attributes compared to unattractive people. This sort of stable perception associated with physical attractiveness has been described as famous "what is beautiful is good" stereotype [4]. As was confirmed in a meta-analytical study [5] people describe individuals with beautiful faces along positive lines. Typical attractiveness components include averageness [6], symmetry [7] [8], sexual dimorphism [9], skin quality [10], a pleasant expression, good grooming [11], youth [12], and, for known faces, attractiveness can reflect nonphysical characteristics, such as how much one likes the person [13]. There may also be different kinds of attractiveness (e.g., sexual attractiveness, attractiveness as a potential ally, cuteness) with different affective and motivational consequences [11]. 
The most selected preferences are [3]: 1. preference for proximity to a spatially average face, i.e. averageness; 2 . preference for bilateral symmetry, and 3. preference for feminine traits in female faces and masculine traits in male faces. From psychological point of view, an important cross-cultural confirmed conclusion suggests that personality traits are (by both sexes) reported as to be one of the most important factors in partner choice [14] [15]. Therefore, it could be assumed that personality attributions elicited by a face would impact on its attractiveness, thus, it may be that the personality attributions are driving the attractiveness judgements [16]. An assumption that perceived personality differences elicited by face traits could play an important role in attractiveness judgements is theoretically important as it provides a new way to interpret the "what is beautiful is good" stereotype. Based on the fact women find as desirable what they consider good, and they perceive faces with desired traits attractive, it can be hypothesized that facial attractiveness reflects "what is good is beautiful" reversing the causal logic of "what is beautiful is good" [16]. Moreover, regardless of the potential inaccuracy of personality attributions, many individuals do believe the face is an important source of information about one's character [17]. People differ in their preferences for personality in partners and given the importance of personality in a partner, personality inferences about a face may influence that face's attractiveness [14].

No straightforward consensus has come to light in the preference for masculine/feminine male face. Although it could be expected (and some studies have confirmed it [18]) that there is a clear preference for more masculine male faces, other research has shown some exceptions where feminised male faces were found more attractive [19] [20]. More masculine men are considered healthier [21], but on the other hand these men are characteristic by negatively perceived personality traits as lower honesty and lower warmth [20]. Very attractive male faces possess a combination of both masculine and feminine features, and therefore reflect 'multiple motives' in a woman's choice of partner, i.e. the desire for a dominant and a cooperative partner [19]. Further, the women's attraction to masculine traits in a men's face variates during the menstrual cycle [22] [23], the relationship is the strongest when women are most fertile, during late follicular cycle phase respectively. It can be assumed, that women are more interested in "good genes" when more fertile, and they are more interested in a cooperative partner when they are in the luteal phase of the menstrual cycle.

Female faces with feminine features in the face are generally evaluated as attractive [24] [25] by both, men and women. Results from research analysing facial composites of women [20] and photographs of women [26] have come to similar conclusion, that is, feminine traits of female faces increase the attractiveness evaluation. As it appears, the attractivity evaluation of female faces is as well connected to the changes during menstrual cycle of women. Feminine women's faces as well as feminine men's faces are considered to be good parents and trustworthy [20], therefore it can be assumed, that women who are in the more fertile phase of their menstrual cycle prefer women (and possibly their faces) who are more likely to provide support during pregnancy. Fertile phase is associated with women's preferences for self-similar female faces [27].

Lastly, there is a possible relationship between personal situation of the female and her evaluation of the face attractiveness. Women in a relationship have a preference for more masculine faces in general, and women using oral contraception don't show any significant cyclic shifts in their preference [28].

The current study compares women's preference for masculinity in male and female faces according to menstrual cycle phase, contraceptives intake, and actual partnership. We have tested these relationships with women's face preferences: menstrual cycle phase (follicular or luteal phase), reported commitment to romantic relationship, and usage of oral contraceptives.

\section{METHODS}

\section{Participants}

288 women participated in the research. From them, 28 women don't have menstrual cycle, and 260 women have menstrual cycle, therefore only the latter group's data are analysed. The mean age is 21.23 years $(\mathrm{SD}=6.135$ ). The group reported regular menstrual cycle (cycle length: $\mathrm{M}=28.45$, $\mathrm{SD}=3.743$ ). $66.7 \%$ of the women reported not to use oral contraceptives. $55.2 \%$ of the women reported having a partner. 
The participants filled out a battery of questionnaires and performance tasks among which they had to evaluate the attractiveness of a face according to his/her masculinity/femininity. Preferences of male and female face images are analysed.

\section{Processed variables}

Sex - Participants were asked to choose from two categories of sex. This research analyses only women.

Attractiveness of masculinity/femininity of faces - The face composites have been used for face attractiveness assessment based on masculinity/femininity perception [29]. Two male and two female composites showed faces manipulated in facial masculinity and femininity in compliance with face features corresponding with high masculinity and femininity in faces. Women, who evaluated the faces according to their attractiveness were blind to the fact that faces represent two different levels of masculinity/femininity. Women were asked to answer the question: "Which face do you like more?" The task was to choose from two possibilities: a face with masculine traits or a face with feminine traits. Face composites are shown at the figure 1.

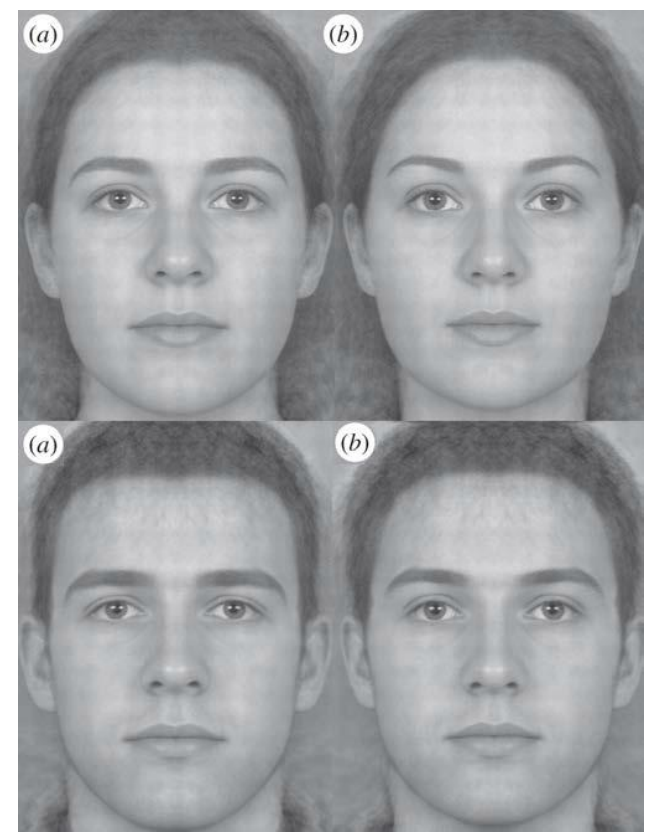

Figure1. Face composites manipulated in facial masculinity and femininity. Faces marked a) masculinized faces, b) feminized faces [29]

Menstrual cycle phase - Information of the menstrual cycle phase was computed from 4 items: the presence of menstruation, the length of menstruation, the length of menstrual cycle, and the last date of the menstruation. The resulting variable is luteal/follicular phase of the woman.

Oral contraception - Participants were asked to choose from two possibilities (yes/no) on the question if they use oral contraceptives at present.

Actual partnership - Participants were asked to answer the question if they are in a romantic partnership at present.

\section{RESUlts}

First part of analysis is concentrated on differences in the attractiveness evaluation of masculine/feminine man's face according to menstrual cycle phase of the judge (Table 1). The assumption tested that women who are in the follicular phase prefer masculine men faces $\left(\mathrm{X}^{2}=1.621\right.$, sig=0.101), as visible the difference between menstrual cycle phases and the preference of masculine/feminine face is non-significant. Masculine male's face is slightly more preferred $(\mathrm{N}=135$; $52.1 \%$ ) in general by both groups of women, but the difference didn't show important. 
Different results are provided by the comparison of menstrual cycle phase of the women and their evaluation of the attractiveness of masculine/feminine woman's face (Table 1). It is expected that fertile phase of the menstrual cycle is associated with women's preferences for self-similar female faces, more precisely for feminine faces. In general, feminine female's face is preferred by the majority of women (76.9\%). The difference between women in two menstrual cycle phases and the preference of masculine/feminine female face is significant $\left(X^{2}=11.257\right.$, sig $\left.=0.000\right)$, the presumption of preference of feminine female faces during follicular phase due to expected kinship is tenable. During the follicular phase women tend to prefer the feminine face slightly more $(\mathrm{N}=116 ; 85.3 \%)$ in comparison to women who are in the luteal phase $(\mathrm{N}=84 ; 67.7 \%)$.

Table1. Independent Chi-Square for the menstrual cycle phase and attractiveness of the images of faces

\begin{tabular}{|c|c|c|c|c|c|}
\hline \multicolumn{6}{|c|}{ Male face assigned as the most attractive } \\
\hline $\begin{array}{l}\text { Menstrual } \\
\text { cycle phase }\end{array}$ & Masculine & Feminine & Total & Phi & Sig. \\
\hline $\begin{array}{c}\text { Follicular } \\
\text { phase }\end{array}$ & $\begin{array}{c}76 \\
55.9 \%\end{array}$ & $\begin{array}{c}60 \\
44.1 \%\end{array}$ & 136 & 0.079 & 0.101 \\
\hline Luteal phase & $\begin{array}{c}59 \\
48.0 \%\end{array}$ & $\begin{array}{c}64 \\
52.0 \%\end{array}$ & 123 & & \\
\hline Total & $\begin{array}{c}135 \\
52.1 \%\end{array}$ & $\begin{array}{c}124 \\
47.9 \%\end{array}$ & 259 & & \\
\hline \multicolumn{6}{|c|}{ Female face assigned as the most attractive } \\
\hline $\begin{array}{l}\text { Menstrual } \\
\text { cycle phase }\end{array}$ & Masculine & Feminine & Total & Phi & Sig. \\
\hline $\begin{array}{c}\text { Follicular } \\
\text { phase }\end{array}$ & $\begin{array}{c}20 \\
14.7 \% \\
\end{array}$ & $\begin{array}{c}116 \\
85.3 \% \\
\end{array}$ & 136 & -0.208 & 0.000 \\
\hline Luteal phase & $\begin{array}{c}40 \\
32.3 \% \\
\end{array}$ & $\begin{array}{c}84 \\
67.7 \% \\
\end{array}$ & 124 & & \\
\hline Total & $\begin{array}{c}60 \\
23.1 \%\end{array}$ & $\begin{array}{c}200 \\
76.9 \%\end{array}$ & 260 & & \\
\hline
\end{tabular}

Next part of analysis is focused on the attractiveness evaluation of masculine/feminine faces according to the menstrual cycle phase of the women with regards to their contraceptive use and actual partnership. The presumption towards women using oral contraception is, that they don't show any significant cyclic shifts in their preference of masculine or feminine face, and women who are in a stable romantic relationship tend to prefer more masculine faces.

As it appears the usage of oral contraception has an important influence on the attractiveness evaluation of both woman and man's face. Usage of oral contraception eliminates the differences present in natural menstrual cycle, as we confirmed in this research too. There are no significant differences in the evaluation of masculine/feminine male face (X2=0.471, sig=0.493) or masculine/feminine female face $\left(X^{2}=2.139, \mathrm{sig}=0.144\right.$, sig $\left._{\text {Fisher's exact test }}=0.209\right)$ between the menstrual cycle phase among women who use oral contraceptives and are not currently in a relationship. Neither there are differences among women who use oral contraceptives and are in a romantic relationship in the evaluation of masculine/feminine male face $\left(X^{2}=0.468\right.$, sig $\left.=0.494\right)$ or masculine/feminine female face $\left(X^{2}=0.059, \operatorname{sig}=0.807\right.$, sig $\left._{\text {Fisher's exact test }}=0.529\right)$.

Interesting results have arisen from the current situation of the women as well. If a woman doesn't use oral contraceptives, the presence of her romantic relationship gains on it's importance. In the situation of natural menstrual cycle, the evaluation of a man's face is dependent on the presence of romantic relationship (Table 3). Women who are not in a romantic relationship display shifts in the menstrual cycle phase when evaluating a man's face $\left(X^{2}=2.673 \mathrm{sig}=0.05\right)$, during the follicular phase a masculine man's face is preferred by $52.3 \%$ of women $(\mathrm{N}=23)$, whilst during the luteal phase a masculine face is preferred only by $34.9 \%$ of the women $(\mathrm{N}=15)$. On the other hand, if a woman is in a relationship, there are no significant differences between the preference of a masculine of a feminine man's face according to the menstrual cycle phase $\left(\mathrm{X}^{2}=0.121\right.$ sig= 0.364$)$, simultaneously, as expected the masculine man's face is slightly more preferred in general $(55.6 \%)$. 
Masculinity and Femininity in the Attractiveness of Human Face's Preference According to Menstrual Cycle Phase, Contraceptives Intake, and Actual Partnership

Table2. Independent Chi-Square for the menstrual cycle phase and attractiveness of male face evaluated by women who don't use oral contraception and are in a romantic relationship or are not in a romantic relationship

\begin{tabular}{|c|c|c|c|c|c|}
\hline \multicolumn{6}{|c|}{ Women not in a romantic relationship } \\
\hline \multirow{2}{*}{$\begin{array}{l}\text { Menstrual } \\
\text { cycle phase }\end{array}$} & \multicolumn{5}{|c|}{ Male face assigned as the most attractive } \\
\hline & Masculine & Feminine & Total & Phi & Sig. \\
\hline $\begin{array}{c}\text { Follicular } \\
\text { phase }\end{array}$ & $\begin{array}{c}23 \\
52.3 \%\end{array}$ & $\begin{array}{c}21 \\
47.7 \%\end{array}$ & 44 & \multirow[t]{3}{*}{0.175} & \multirow[t]{3}{*}{0.05} \\
\hline Luteal phase & $\begin{array}{c}15 \\
34.9 \% \\
\end{array}$ & $\begin{array}{c}28 \\
65.1 \%\end{array}$ & 43 & & \\
\hline Total & $\begin{array}{c}38 \\
43.7 \% \\
\end{array}$ & $\begin{array}{c}49 \\
56.3 \% \\
\end{array}$ & 87 & & \\
\hline \multicolumn{6}{|c|}{ Women in a romantic relationship } \\
\hline \multirow{2}{*}{$\begin{array}{l}\text { Menstrual } \\
\text { cycle phase }\end{array}$} & \multicolumn{5}{|c|}{ Male face assigned as the most attractive } \\
\hline & Masculine & Feminine & Total & Phi & Sig. \\
\hline $\begin{array}{c}\text { Follicular } \\
\text { phase }\end{array}$ & $\begin{array}{c}23 \\
57.5 \%\end{array}$ & $\begin{array}{c}17 \\
42.5 \%\end{array}$ & 40 & \multirow[t]{3}{*}{0.039} & \multirow[t]{3}{*}{0.364} \\
\hline Luteal phase & $\begin{array}{c}22 \\
53.7 \%\end{array}$ & $\begin{array}{c}19 \\
46.3 \%\end{array}$ & 41 & & \\
\hline Total & $\begin{array}{c}45 \\
55.6 \%\end{array}$ & $\begin{array}{c}36 \\
44.4 \%\end{array}$ & 81 & & \\
\hline
\end{tabular}

Assessment of the attractiveness of a female's face image was tested in the same condition as above; in natural menstrual cycle. The assessment of a female face is not influenced by the presence of a romantic relationship. There are significant differences between women in follicular and luteal phase in their preference of masculine and feminine female's face if they are in a relationship and as well if they are not in a relationship. As expected, women not in a relationship prefer during their follicular phase prevailingly feminine female's image $(88.6 \%)$, whistle during the luteal phase a feminine female face is preferred by $56.8 \%$ of the women. Mentioned difference is significant $\left(\mathrm{X}^{2}=11.229\right.$, sig=0.000). If a woman is in a romantic relationship the preference of a feminine female face in follicular phase is higher as well $(87.5 \%)$ compared to the luteal phase. This difference is as well significant $\left(\mathrm{X}^{2}=3.433\right.$, sig=0.032).

Table3. Independent Chi-Square for the menstrual cycle phase and attractiveness of female's face image evaluated by women who don't use oral contraception and are in a romantic relationship or are not in a romantic relationship

\begin{tabular}{|c|c|c|c|c|c|}
\hline \multicolumn{6}{|c|}{ Women not in a romantic relationship } \\
\hline \multirow{2}{*}{$\begin{array}{l}\text { Menstrual } \\
\text { cycle phase }\end{array}$} & \multicolumn{5}{|c|}{ Female face assigned as the most attractive } \\
\hline & Masculine & Feminine & Total & Phi & Sig. \\
\hline $\begin{array}{c}\text { Follicular } \\
\text { phase }\end{array}$ & $\begin{array}{c}5 \\
11.4 \%\end{array}$ & $\begin{array}{c}39 \\
88.6 \%\end{array}$ & 44 & \multirow[t]{3}{*}{-0.357} & \multirow[t]{3}{*}{0.000} \\
\hline Luteal phase & $\begin{array}{c}19 \\
43.2 \%\end{array}$ & $\begin{array}{c}25 \\
56.8 \%\end{array}$ & 44 & & \\
\hline Total & $\begin{array}{c}24 \\
27.3 \%\end{array}$ & $\begin{array}{c}64 \\
72.7 \%\end{array}$ & 88 & & \\
\hline \multicolumn{6}{|c|}{ Women in a romantic relationship } \\
\hline \multirow{2}{*}{$\begin{array}{c}\text { Menstrual } \\
\text { cycle phase }\end{array}$} & \multicolumn{5}{|c|}{ Female face assigned as the most attractive } \\
\hline & Masculine & Feminine & Total & Phi & Sig. \\
\hline $\begin{array}{l}\text { Follicular } \\
\text { phase }\end{array}$ & $\begin{array}{c}5 \\
12.5 \%\end{array}$ & $\begin{array}{c}35 \\
87.5 \%\end{array}$ & 40 & -0.206 & 0.032 \\
\hline Luteal phase & $\begin{array}{c}12 \\
29.3 \%\end{array}$ & $\begin{array}{c}29 \\
70.7 \%\end{array}$ & 41 & & \\
\hline Total & $\begin{array}{c}17 \\
21.0 \%\end{array}$ & $\begin{array}{c}64 \\
79.0 \%\end{array}$ & 81 & & \\
\hline
\end{tabular}

\section{DisCUSSION}

Current study has shown that women have different preferences in humans' faces in relation to menstrual cycle phase, and partnership. Oral contraceptive intake appears to be important as well, since it eliminates the differences in evaluation of the human face during menstrual cycle change. 
The preference of male face is inclined slightly in favour to a masculine male face in comparison to the feminine male face, as $52.1 \%$ of the women prefer masculine male face. It can be contemplated, that this result mirrors the multiple motives in woman's choice of partner [19], as the preference of masculinity to gain genetic benefits of the potential partner to offspring [30], and, on the other hand the preference of femininity which is associated with good partnership benefits. The women's preference of masculine traits in a men's face haven't been proven to variate during the menstrual cycle in this research in general as proposed [22]. But when analysing only the group of women with a natural menstrual cycle, we have proven that the relationship is present when women are fertile (during the follicular cycle) in compliance with other research [23]. Therefore it can be assumed, that during the fertile phase of the menstrual cycle women tend to prefer masculinity in men in order to gain genetic advantage for their potential offspring. It is desirable for a woman to obtain both advantages - paternal care and heritable benefits for the offspring [20].

As has been found in this research, women who don't use oral contraception and don't have a stable partner demonstrate shifts in the menstrual cycle phase when evaluating a man's face. While if they have a partner at present these differences are eliminated. It can be assumed that this change in the pattern of masculine preference during the follicular cycle in a relationship is due to the biochemical changes present while building a partnership. In the first stages of partnership, dopamine stimulates the reward centres in the brain [31] and therefore supports a feeling of pleasure. Dopamine and nor adrenaline produce the elevated feeling a person experience when involved in a partnership. It is also associated with suppressed activity of central serotonin. Together they produce a range of emotions and motivations common to romantic love [32]. The process of the social bonding formation, attachment growing and, mainly sustaining is connected to elevated levels of oxytocin and vasopressin [33]. Oxytocin ensures that parents engage in care and stabilization of loving relationship. It leads to relaxed physiological stage that allows consensual sexual behaviour for example. On the other hand, vasopressin is associated with physical and emotional mobilization, which is needed in guarding the partner or territory. Their coexistence allows the care-taking a protective aggression. It can be assumed, that mentioned biochemical changes may result in the elimination of women's' masculine face preference during partnership. As sustaining a bond with a partner may decrease the need for genetic benefits which could be possibly obtained from a masculine partner.

Our study has shown that the use of oral contraception eliminates the differences in masculinity traits preferences which occur in natural menstrual cycle. In compliance with other research [28], women using contraception don't show cyclic shifts understood as adaptive preferences for attractiveness assessments of masculinity. The possible explanation apart from the hormonal changes while using oral contraceptives are different lifestyle choices, as it appears women who use oral contraception reported having more lifetime partners than those not using oral contraception, thus it can be considered it leads to a more promiscuous behaviour [30].

The assessment of female face appears to be more straightforward as in case of man's face preference, in general the most preferred female face is feminine. This finding is in compliance with different researches which have suggested that female faces with feminine traits in the face are evaluated as attractive [20] [24] [25] [26]. It was found out in this research, that the attractivity of female faces is evaluated in concordance with the changes during menstrual cycle. Women in follicular phase prefer feminine female faces more as in luteal phase. As it appears, it doesn't matter if women are in a relationship or not when evaluating other women's' faces, their preference of a feminine female face is higher in follicular phase than in other times. The possible explanation can arise from the idea of kinship, during the fertile phase women prefer self-similar female faces [27], who are likely to provide support during possible pregnancy [20].

The presence of differences among women in their preference of masculinity shows us that women don't generally have an identical idea of an attractive man or a woman. Rather, women are in their attractiveness evaluations influenced by hormonal differences caused by menstrual cycle, by situational factors, such as if they have a partner. As it appears, partnership status of a woman is important for man's attractiveness evaluation.

Results suggest there is a connection between attractiveness assessment and menstrual cycle, the connection is present for both faces' preferences only in natural menstrual cycle (not using hormonal contraceptives) and simultaneously when the women are not in a partnership. Oral contraception appears to be important in the attractiveness evaluation of a human face, because this condition 
eliminates the differences present in natural menstrual cycle. The fact, that preference differences are not present in women who use oral contraception suggests that the preference changes are due to the hormonal status and also that oral contraceptive use may influence a woman's choice of mate [30].

\section{REFERENCES}

[1] Aharon, I. et al. Beautiful faces have variable reward value: fMRI and behavioral evidence. Neuron 32, 537-51 (2001).

[2] O'Doherty, J. et al. Beauty in a smile: the role of medial orbitofrontal cortex in facial attractiveness. Neuropsychologia, 41,147-55 (2003).

[3] Rhodes, G., Simmons, L., and Peters, M. Attractiveness and sexual behaviour: Does attractiveness enhance mating success? Evolution and Human Behavior, 26, 186-201 (2005).

[4] Dion, K., Berscheid, E., \&Walster, E. What is beautiful is good. Journal of Personality and Social Psychology, 24, 285-90 (1972).

[5] Langlois, J. H., et al. Maxims or myths of beauty? A meta-analytic and theoretical review. Psychological Bulletin, 126, 390-423 (2000).

[6] Langlois, J. H., Roggman, L. A., and Musselman, L. What is average and what is not average about attractive faces? Psychological Science, 5 (4), 214-220 (1994).

[7] Demuthova, S. Vybrané aspekty atraktivity a ich biologické korene. [The selected aspects of the attractiveness and their biological basics.] In H. Záškodná (Ed.) Afiliace 2006: sborník príspěvků. [Affiliation 2006: Collection of Contributions. Ceske Budejovice: Jihoceska univerzita, 1-3 (2007).Zaidel, D. W. and Hessamian, M. Asymmetry and symmetry in the beauty of human faces. Symmetry, 2(1), 136-149 (2010).

[8] Rhodes, G., Hickford, C., \& Jeffrey, L. (2000). Sex-typicality and attractiveness: Are supermale and superfemale faces super-attractive? British Journal of Psychology, 91(1), 125-140.

[9] Fink, B., Bunse, L., Matts, P. J., and D’Emiliano, D. Visible skin colouration predicts perception of male facial age, health and attractiveness. International Journal of Cosmetic Science, 34, $307-$ 31 (2012).

[10] Rhodes, G. The Evolutionary Psychology of Facial Beauty. Annual Review of Psychology, 57, 199-226 (2006).

[11] Ebner, N. C. Age of face matters: age-group differences in ratings of young and old faces. Behav. Res. Methods,40(1), 130-136 (2008).

[12] Kniffin, K., and Wilson, D.S. The effect of nonphysical traits on the perception of physical attractiveness: three naturalistic studies. Evolution and Human Behavior, 25, 88-101 (2004).

[13] Buss, D. M. Sex differences in human mate preferences: Evolutionary hypotheses tested in 37 cultures. Behavioural and Brain Sciences, 12, 1-49 (1989).

[14] Buss, D. M., and Barnes, M. Preferences in human mate selection. Journal of Personality and Social Psychology, 50, 559-570 (1986).

[15] Little, A. C., Burt, D. M., and Perrett, D. I. What is good is beautiful: Face preference reflects desired personality. Personality and Individual Differences, 41, 1107-1118 (2006).

[16] Hassin, R., and Trope, Y. Facing faces: Studies on the cognitive aspects of physiognomy. Journal of Personality and Social Psychology, 78, 837-852 (2000).

[17] Grammer, K., and Thornhill, R. Human (homo sapiens) facial attractiveness and sexual selection: The role of symmetry and averageness. Journal of Comparative Psychology, 108, 233-242 (1994).

[18] Cunningham, M. R., Barbee, A. P., and Pike, C. L. What do women want? Facialmetric assessment of multiple motives in the perception of male facial physical attractiveness. Journal of Personality and Social Psychology, 59 (1), 61-72 (1990).

[19] Perrett, D. I. et al. Effects of sexual dimorphism on facial attractiveness. Nature, 394, 884-887 (1998).

[20] Folstad, I. and Karter, A. J. Parasites, bright males and the immunocompetence handicap. Am. Nat. 139, 603-622 (1992). 
[21] Johnston, V.S., Hagel, R., Franklin, M., Fink, B., and Grammer, K. Male facial attractiveness: evidence for a hormone-mediated adaptive design. Evol. Hum. Behav, 22, 251- 267 (2001).

[22] Penton-Voak, I.S., and Perrett, D.I. Female preference for male faces changes cyclically - further evidence. Evol. Hum. Behav. 21, 39- 48 (2000).

[23] Cornwell, E. R., Boothroyd, L., Burt, D. M., and Perrett, D. I. Concordant preferences for opposite-sex signals? Human pheromones and facial characteristics. Proceedings of the Royal Society B. Biological Sciences, 271(1539), 635-640 (2004).

[24] Little, A. C., Jones, B. C., Feinberg, D. R., and Perrett, D. I. Men's strategic preferences for femininity in female faces. British Journal of Psychology, 105(3), 364-381 (2014).

[25] Jones, D. and Hill, K. Criteria of facial attractiveness in five populations. Human Nature, 4(3), 271-296 (1993).

[26] DeBruine, L.M., Jones, B.C., Perrett, D.I. Women's attractiveness judgments of self-resembling faces change across the menstrual cycle. Hormonal Behaviour, 47, 379-383 (2005).

[27] Penton-Voak, I. S., Perrett, D. I., Castles, D. L., Burt, D. M., Kobayashi, T., Murray, L. K. and Minamisawa, R. Menstrual cycle alters face preference. Nature, 399, 741-742 (1999).

[28] Little, A. C., Jones, B. C., and DeBruine, L. M. Facial attractiveness: evolutionary based research. In Anthony C. Little, Benedict C. Jones \& Lisa M. DeBruine (Eds.), Face perception: social, neuropsychological and comparative perspectives. Philosophical Transactions of the Royal Society B. Biological Sciences, 366(1571), 1633-1777 (2011).

[29] Little, A. C., Jones B. C., Penton-Voak I. S., Burt, D. M., and Perrett D. I. Partnership status and the temporal context of relationships influence human female preferences for sexual dimorphism in male face shape. Proc. R. Soc. Lond. B, 1095-1100 (2002).

[30] Fisher, H. Lust, attraction and attachment in mammalian reproduction. Human Nature, 9 (1), 23 52 (1998).

[31] Fisher, H. Why We Love: The Nature and Chemistry of Romantic Love. New York: Henry Holt (2004).

[32] Lim, M.M., Wang, Z., Olazábal, D.E. Ren, X., Terwilliger, E. F., and Young, L.J. Enhanced partner preference in a promiscuous species by manipulating the expression of a single gene. Nature, 17, 754-757 (2004).

\section{AUTHOR'S BIOGRAPHY}

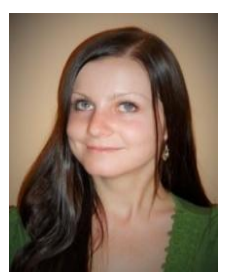

Lenka Selecká, PhD. She has gained $\mathrm{PhD}$. degree in social psychology and psychology of work in 2013. She is a postdoc assistant professor and researcher working at University of Ss. Cyril and Methodius in Trnava, Slovakia. Her research is focused on psychometrics, individual psychology, and social psychology. 